\title{
Increased Chromosome Fragility in Gastric Cancer Patients
}

\author{
Petros Kouridakis ${ }^{1}$, Evangelos Digkas ${ }^{1}$, Georgios Kouklakis ${ }^{2}$, Georgios Minopoulos ${ }^{2}$, Alexandros \\ Polychronidis ${ }^{3}$, Nikolaos Lyratzopoulos ${ }^{3} \&$ Theodoros S Lialiaris $^{1}$ \\ ${ }^{1}$ Laboratory of Genetics, Demokrition University of Thrace, 68100 Alexandroupolis, Greece \\ ${ }^{2}$ Gastrointestinal Endoscopy Unit, Demokrition University of Thrace, 68100 Alexandroupolis, Greece \\ ${ }^{3} 1^{\text {st }}$ Dept of Surgery, University General Hospital, Demokrition University of Thrace, 68100 Alexandroupolis, \\ Greece
}

Correspondence: Theodore S. Lialiaris, Address: Medical School, University Camp, Dragana, 68100 Alexandroupolis, Greece. Tel/Fax: 30-255-103-0522. E-mail: lialiari@med.duth.gr

Received: January 29, 2012 Accepted: February 5, 2012 Online Published: May 1, 2012

doi:10.5539/cco.v1n1p148 URL: http://dx.doi.org/10.5539/cco.v1n1p148

\begin{abstract}
Gastric cancer is one of the most common lethal malignancy in global and survival mainly depends on prognosis. Sister Chromatid Exchanges (SCEs) assay is a very sensitive method of detecting chromosome fragility. The aim of our study was to determine the chromosomal fragility of gastric cancer patients in vitro. Samples from 32 gastric cancer patients and 12 healthy donors were controlled. Cancer patients lymphocytes' genome is highly fragile as treatment of the cell cultures with MMC caused a statistically significant increase of the mean SCEs frequency $(\mathrm{p}<0.01)$. Also, so simultaneous as MMC-induced SCEs frequency of gastric cancer patients was statistically significant $(\mathrm{p}<0.01)$ higher compared to the healthy donors. PRI and MI of treated with MMC and untreated lymphocytes of gastric cancer patients were significantly $(p<0.01)$ lower than that of healthy donors. These results suggest that peripheral lymphocyte chromosomes of cancer patients are highly fragile and alkyliotic agents increase their fragility.
\end{abstract}

Keywords: gastric cancer, Sister Chromatid Exchanges (SCEs), Mitomycin C, chromosome fragility

\section{Introduction}

Gastric cancer is the third most common malignancy worldwide and the second most common cause of cancer related mortality (Parkin et al., 2001). The prognosis of patients at the advanced stage is very low. Gastric cancer as all other types of cancer is the result of multiple genetic abnormalities accumulated during the process of carcinogenesis. The molecular mechanism of multi-step carcinogenesis is poorly understood (Vogelstein and Kinzler, 2004; Yasui et al., 2001). It has been shown that the development of gastric cancer is a multi-step process starting from chronic gastritis passing to atrophy, intestinal mataplasia, dysplasia and finally to invasive cancer (Pasechnikov et al., 2004; Testino, 2004). Many genes polymorphisms have been proposed to be implicated in gastric cancer, such as TLR gene cluster of Toll-like receptor, Igk gene and p53 (Hu et al., 2008; Etokebe et al., 2009; Ke-Xiang et al., 2012).

Mitomycin C (MMC) is an antibiotic with anti-tumor applications in combination with other antineoplastic drugs (Beijnen et al., 1986) and it is considered as an original alkylating agent (Sartorelli, 1986). MMC acts on the DNA and increases SCEs, induced in specific chromosomal regions, as it has been reported that MMC increases SCEs mainly at fragile chromosome domains (Wenger, 1995). MMC has been extensively used in chromosomal fragility studies in order to investigate if some conditions, such as diseases and various physical, chemical and biological agents affect its mutagenic efficiency (Latt et al., 1975; Ohtsuru et al., 1980; Duydu et al., 2006; Digkas et al., $2010^{\mathrm{a}}$ ). The existence of sister chromatid exchanges (SCEs) connects to DNA replication, and their analysis is an excellent tool for the quantitative and qualitative evaluation of the DNA damage caused by physical, chemical or biological mutagenic agents (Lialiaris et al., 1987; Lialiaris et al., 2010; Digkas et al., $\left.2010^{\mathrm{b}}\right)$.

SCEs are symmetric exchanges between portions of apparently homologous sister chromatids and are formed through DNA breakage and subsequent reunion. The method of Sister Chromatid Exchanges (SCEs) has been proposed as a very sensitive, simple and rapid method for detecting DNA damage induced by mutagens and/or carcinogens and antimutagenic agents and/or subsequent DNA repair, while its application is very useful for 
monitoring and improving chemotherapeutic efficiency in vitro and in vivo. SCEs are considered as a more sensitive method than chromosome aberrations since induced DNA damage can be demonstrated by the formation of SCEs even at low concentrations of genotoxic agent (Lialiaris et al., 1989; Lialiaris et al., 1990; Papachristou et al., 2006; Lialiaris et al., 2008). They are present in all humans but in low frequencies (Aristei et al., 2009). High frequencies of SCEs are formed in patients suffering from several cancer types (Dhillon et al., 1995; Dhillon et al., 1996; Dhillon and Dhillon, 1998; Dhar et al., 1996; Cortes-Gutierrez et al., 2000; Cefle et al., 2006; Aristei et al., 2009; Baka et al., 2009). Smoke, age and other genotoxic agents cause high frequencies in SCEs to humans (Sarto et al., 1985; Sarto et al., 1987).

The aim of our study was to determine the chromosomal fragility, by counting SCEs frequency in peripheral lymphocytes of gastric cancer patients.

\section{Materials and Methods}

\subsection{Chemicals}

Mitomycin C (CAS No. 50-07-7) was obtained from Kyowa, Heparin (CAS No. 9005-49-6) from Seromed, Chromosome Medium B from Biochrom AG (CAS No. 23491-52-3), 5-Bromo-2'-deoxyuridine (BrdU, CAS No. 59-14-3) from Sigma and Bis-benzimide (Hoechst) from Applichem, Colcemid (CAS No. 477-30-5) from Seromed. All of the chemicals were dissolved in bidistilled sterile water and lower concentrations needed were prepared by serial dilutions just before treatment. Other chemicals used in the SCEs assay were of the best grade commercially available.

\subsection{Clinical Data}

At the beginning of our study, we had 32 patients with mean age 65 years (55-76) suffering from gastric cancer, none of them was having medication or other treatment. All of them were going to have surgery for the gastric cancer. Also 12 healthy persons with mean age 60 years old, who did not take any medication and did not smoke, were used as negative control. Peripheral blood was obtained from patients and healthy donors and cultured in order to study the effect of gastric cancer on peripheral lymphocytes DNA by using the SCEs technique.

\subsection{In vitro Sister Chromatid Exchange Analysis}

Lymphocyte cultures, for SCEs assay, from our patients were prepared by adding 11 drops of heparinized whole blood, $4 \mu \mathrm{g} / \mathrm{ml} \mathrm{BrdU}$ and $2 \%$ phytohaematogglutin (PHA) in $5 \mathrm{ml}$ chromosome medium B. From the peripheral blood of each donor there were made two lymphocyte cultures one used as control and one were MMC was added in concentration of $15 \mathrm{ng} / \mathrm{ml}$ in order to check the fragility of the chromosomes. The cultures were incubated at $37^{\circ} \mathrm{C}$ for 72 hours in dark to minimize photolysis of BrdU and metaphases were blocked during the last two hours with colcemid. Further processing included hypotonic treatment, with $0.075 \mathrm{KCl}$ solution, for 25 minutes, which spreads and hemolyzes the red blood cells, centrifugion, fixation for three times with methanol:acetic acid (3:1 v/v) slide preparation and a slightly changed Fluorescence Plus Giemsa (FPG) staining technique for the detection of SCEs (Figure1) (Goto et al., 1978). 


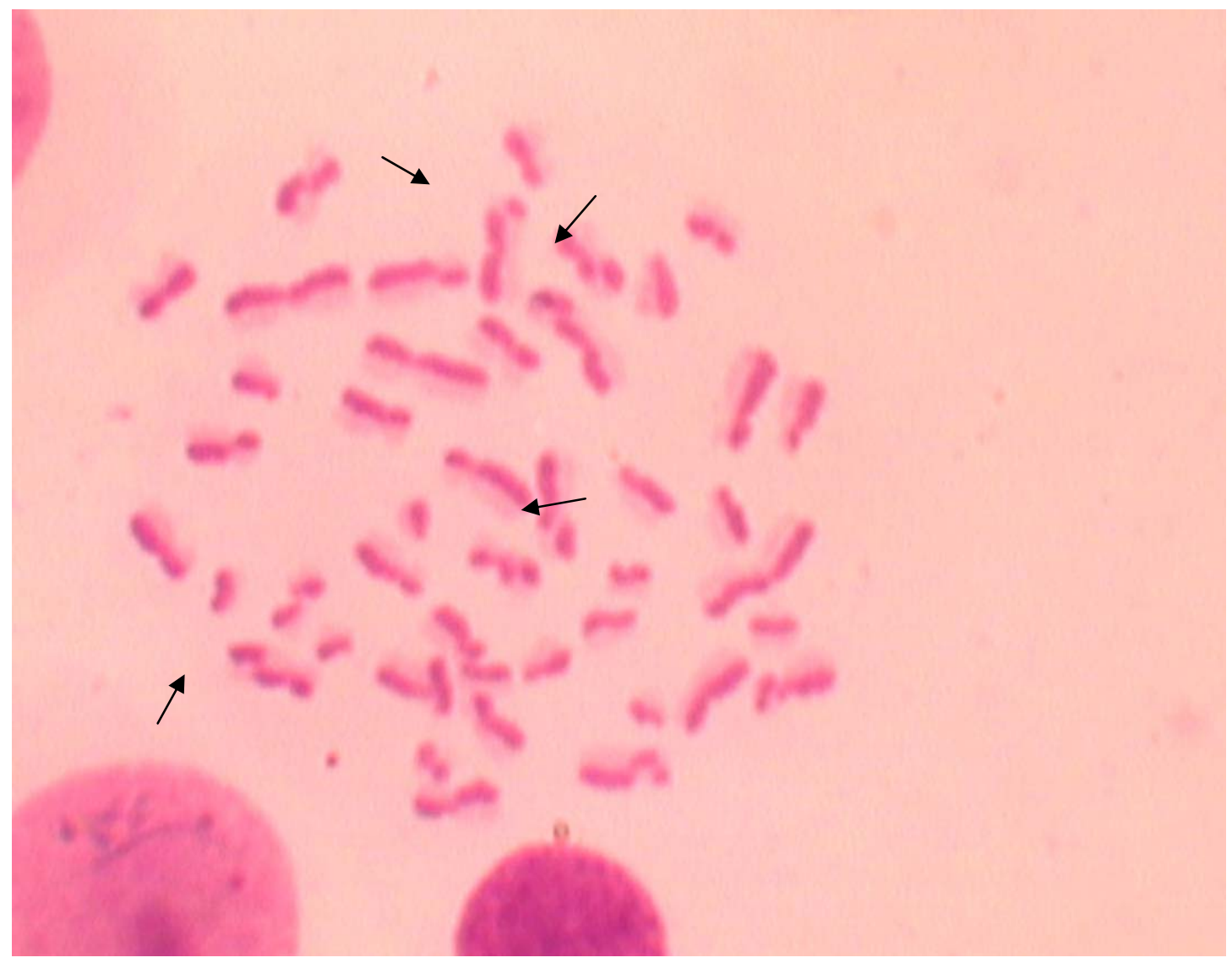

Figure 1. A second division of a human lymphocyte metaphase in presence of MMC, where all chromosomes have in total one light and one dark stained chromatid. SCEs can be counted only in these metaphases. Black arrows show single SCEs.

\subsection{Statistical Analysis}

To achieve a proper comparison between the different lymphocyte treatments, 20 well spread second division metaphases from each culture were blindly scored and logarithmic transformations of SCEs was performed using the one-way analysis of variance and the Duncan's test for the pairwise comparisons. Evaluation of MIs and PRIs was based on the $\chi^{2}$-test. Bivariance correlations between SCEs and MIs or SCEs and PRIs were also calculated (Lialiaris et al., 2009; Karapidaki et al., 2009).

\section{Results}

SCEs frequency, PRI and MI values of lymphocyte cultures from gastric cancer patients immediately after the diagnosis and before any treatment are illustrated in Table 1, whereas the values of the same indices for lymphocyte metaphases derived from healthy donors and used as controls are illustrated in Table 2. Values in baseline of each column are the mean values for each in vitro treatment of chromosome preparations derived from the two groups examined, the gastric cancer patients and the healthy donors. Each value of SCEs in Tables 1 and 2 is the mean value of at least 20 metaphases in the second mitotic division. Also each PRI value in the two tables is the mean value of at least 200 metaphases whereas each MI value is the mean value of at least 2000 mesophasic nuclei.

As shown in Table 1 the levels of SCEs in chromosomes of gastric cancer patients are quite high with a mean value of 6.691 SCEs per metaphase. When MMC was added in lymphocyte cultures SCEs were increased significantly $(\mathrm{p}<0.01)$ and reached a mean value of 16.056 SCEs per metaphase showing that the antibiotic's genotoxic action affects chromosomes fragility significantly as shown by the increased values of SCEs index. The mean PRI value of lymphocytes derived from gastic cancer patients is 2.301. After MMC treatment the PRI value of lymphocyte cultures derived from gastric cancer patients significantly $(\mathrm{p}<0.05)$ decreased, comparing to that of "control" cultures, to 1.742. As shown in Table 1 the MI value for cultured lymphocytes of gastric cancer patients is 40.2 and it was statistically significant $(\mathrm{p}<0.01)$ decreased to 22.3 when MMC was added. 
The SCEs, PRIs and MIs were counted for lymphocytes of healthy individuals and are shown in Table 2. The mean value of the SCEs frequency of lymphocytes of "control" cultures is 3.385 SCEs per cell, which is significantly $(\mathrm{p}<0.01)$ lower than that of lymphocytes treated with MMC $(15 \mathrm{ng} / \mathrm{ml})$ which was calculated 8.647 SCEs/cell. PRI mean value of lymphocytes of "control" cultures is 2.474 and slightly and not statistically significant $(p<0.01)$ lower than that, 2.512 , of cultures where MMC was added. The mean MI value of lymphocytes obtained from healthy donors is 51.1, whereas the value of the same index for lymphocytes from the same donors and treated with MMC is 48.2. Mean MI value of chromosomes of the "control" cultures is not statistically significant $(\mathrm{p}>0.05)$ higher than that of chromosomes of cultures treated with MMC.

Table 1. SCEs frequencies, PRI and MI of peripheral lymphocytes obtained from stomach cancer patients

\begin{tabular}{|c|c|c|c|c|}
\hline Patient & Treatment & SCEs \pm SEM & PRI & MI (\%) \\
\hline \multirow{2}{*}{1} & Control & $6.396 \pm 0.58$ & 2.250 & 44.5 \\
\hline & $\mathrm{MMC}$ & $14.693 \pm 0.79 *$ & $2.065^{*}$ & $20.2^{*}$ \\
\hline \multirow{2}{*}{2} & Control & $4.792 \pm 0.36$ & 2.060 & 37.5 \\
\hline & MMC & $13.694 \pm 0.62 *$ & $1.870^{*}$ & $20.0^{*}$ \\
\hline \multirow{2}{*}{3} & Control & $5.692 \pm 0.37$ & 2.260 & 35.0 \\
\hline & $\mathrm{MMC}$ & $14.890 \pm 0.88^{*}$ & $1.850^{*}$ & $21.2 *$ \\
\hline \multirow{2}{*}{4} & Control & $7.146 \pm 0.43$ & 2.418 & 43.0 \\
\hline & MMC & $15.482 \pm 0.95^{*}$ & $1.740 * * *$ & $23.5^{*}$ \\
\hline \multirow{2}{*}{5} & Control & $8.516 \pm 0.55$ & 2.330 & 32.5 \\
\hline & MMC & $17.766 \pm 1.68^{*}$ & $1.530^{*}$ & $22.5^{*}$ \\
\hline \multirow{2}{*}{6} & Control & $6.550 \pm 0.61$ & 2.236 & 35.0 \\
\hline & MMC & $16.560 \pm 1.43 *$ & $1.704 *$ & $24.5^{*}$ \\
\hline \multirow{2}{*}{7} & Control & $7.632 \pm 0.55$ & 2.170 & 45.0 \\
\hline & MMC & $18.910 \pm 1.71 *$ & $1.590^{*}$ & $23.5^{*}$ \\
\hline \multirow{2}{*}{8} & Control & $7.510 \pm 0.57$ & 2.310 & 45.0 \\
\hline & MMC & $16.932 \pm 1.13^{*}$ & $1.675^{*}$ & $26.0^{*}$ \\
\hline \multirow{2}{*}{9} & Control & $6.734 \pm 0.52$ & 2.530 & 39.0 \\
\hline & MMC & $15.391 \pm 0.93^{*}$ & $1.710^{*}$ & $21.5^{*}$ \\
\hline \multirow{2}{*}{10} & Control & $5.992 \pm 0.47$ & 2.435 & 42.5 \\
\hline & $\mathrm{MMC}$ & $14.279 \pm 0.87^{*}$ & $1.870^{*}$ & $25.0^{*}$ \\
\hline \multirow{2}{*}{11} & Control & $7.904 \pm 0.63$ & 2.350 & 35.0 \\
\hline & MMC & $18.124 \pm 1.15^{*}$ & $1.564 *$ & $15.0^{*}$ \\
\hline \multirow{2}{*}{12} & Control & - & - & 44.0 \\
\hline & MMC & - & - & $20.5^{*}$ \\
\hline \multirow{2}{*}{13} & Control & $5.256 \pm 0.45$ & 2.320 & 40.5 \\
\hline & MMC & $15.251 \pm 1.24 *$ & $1.870^{*}$ & $22.0 *$ \\
\hline \multirow{2}{*}{14} & Control & $7.584 \pm 0.51$ & 2.120 & 39.5 \\
\hline & MMC & $17.431 \pm 1.25^{*}$ & $1.650^{*}$ & $23.5^{*}$ \\
\hline \multirow{2}{*}{15} & Control & $8.216 \pm 0.64$ & 2.405 & 42.0 \\
\hline & $\mathrm{MMC}$ & $17.925 \pm 1.39 *$ & $1.820^{*}$ & $24.0 *$ \\
\hline \multirow{2}{*}{16} & Control & $5.614 \pm 0.41$ & 2.254 & 44.5 \\
\hline & $\mathrm{MMC}$ & $14.325 \pm 1.01^{*}$ & $1.752 *$ & $22.5^{*}$ \\
\hline 17 & Control & $6.469 \pm 0.44$ & 2.324 & 44.0 \\
\hline
\end{tabular}




\begin{tabular}{|c|c|c|c|c|}
\hline & MMC & $15.452 \pm 1.19^{*}$ & $1.650^{*}$ & $25.0^{*}$ \\
\hline \multirow{2}{*}{18} & Control & $4.985 \pm 0.38$ & 2.460 & 37.5 \\
\hline & MMC & $13.958 \pm 0.92 *$ & $1.730^{*}$ & $21.5^{*}$ \\
\hline \multirow{2}{*}{19} & Control & $6.983 \pm 0.47$ & 2.352 & 38.5 \\
\hline & MMC & $14.528 \pm 1.07^{*}$ & $1.925^{*}$ & $20.5^{*}$ \\
\hline \multirow{2}{*}{20} & Control & $7.834 \pm 0.58$ & 2.430 & 37.0 \\
\hline & $\mathrm{MMC}$ & $16.721 \pm 1.19^{*}$ & $1.750^{*}$ & $24.5^{*}$ \\
\hline \multirow{2}{*}{21} & Control & $8.259 \pm 0.62$ & 2.184 & 43.5 \\
\hline & MMC & $18.035 \pm 1.76^{*}$ & 1.820 & $22.0^{*}$ \\
\hline \multirow{2}{*}{22} & Control & $5.211 \pm 0.41$ & 2.092 & 45.0 \\
\hline & MMC & $13.628 \pm 0.87^{*}$ & 1.610 & $23.0^{*}$ \\
\hline \multirow{2}{*}{23} & Control & $7.568 \pm 0.54$ & 2.350 & 42.0 \\
\hline & $\mathrm{MMC}$ & $16.110 \pm 1.14^{*}$ & $1.830^{*}$ & $20.5^{*}$ \\
\hline \multirow{2}{*}{24} & Control & $7.024 \pm 0.47$ & 2.236 & 38.0 \\
\hline & MMC & $16.324 \pm 1.09^{*}$ & $1.725^{*}$ & $22.5^{*}$ \\
\hline \multirow{2}{*}{25} & Control & $6.870 \pm 0.42$ & 2.324 & 36.0 \\
\hline & MMC & $14.180 \pm 0.91^{*}$ & $1.550^{*}$ & $24.5^{*}$ \\
\hline \multirow{2}{*}{26} & Control & $6.910 \pm 0.39$ & 2.185 & 43.0 \\
\hline & $\mathrm{MMC}$ & $17.991 \pm 1.32 *$ & $1.620^{*}$ & $25.0^{*}$ \\
\hline \multirow{2}{*}{27} & Control & $7.345 \pm 0.49$ & 2.224 & 37.5 \\
\hline & $\mathrm{MMC}$ & $17.510 \pm 1.28^{*}$ & $1.710^{*}$ & $23.5^{*}$ \\
\hline \multirow{2}{*}{28} & Control & $5.358 \pm 0.37$ & 2.350 & 44.0 \\
\hline & $\mathrm{MMC}$ & $14.557 \pm 1.03 *$ & $1.750^{*}$ & $22.0^{*}$ \\
\hline \multirow{2}{*}{29} & Control & $6.814 \pm 0.34$ & 2.480 & 42.0 \\
\hline & $\mathrm{MMC}$ & $16.319 \pm 1.17 *$ & $1.850^{*}$ & $23.5^{*}$ \\
\hline \multirow{2}{*}{30} & Control & $7.032 \pm 0.41$ & 2.345 & 37.0 \\
\hline & $\mathrm{MMC}$ & $17.182 \pm 1.31^{*}$ & $1.955^{*}$ & $22.5^{*}$ \\
\hline \multirow{2}{*}{31} & Control & $5.825 \pm 0.39$ & 2.210 & 39.5 \\
\hline & MMC & $13.883 \pm 0.94^{*}$ & $1.630^{*}$ & $21.0^{*}$ \\
\hline \multirow{2}{*}{32} & Control & $8.385 \pm 0.55$ & 2.330 & 40.0 \\
\hline & $\mathrm{MMC}$ & $18.783 \pm 1.71^{*}$ & $1.680^{*}$ & $24.5^{*}$ \\
\hline \multirow{2}{*}{ Mean } & Control & 6.691 & 2.301 & 40.2 \\
\hline & MMC & $16.056^{* *}$ & $1.742 * *$ & $22.3^{* *}$ \\
\hline
\end{tabular}

${ }^{*} \mathrm{p}<0.01$ vs. control of the same gastric cancer patient

$* * p<0.01$ vs. mean control

*** $p<0.05$ vs. control of the same patient 
Table 2. SCEs frequencies, PRI and MI of peripheral lymphocytes obtained from healthy individuals

\begin{tabular}{|c|c|c|c|c|}
\hline Patient & Treatment & SCEs \pm SEM & PRI & MI (\%) \\
\hline \multirow{2}{*}{1} & Control & $2.321 \pm 0.30$ & 2.560 & 55.0 \\
\hline & MMC & $8.951 \pm 0.55^{*}$ & 2.480 & 45.0 \\
\hline \multirow{2}{*}{2} & Control & $3.552 \pm 0.42$ & 2.475 & 47.5 \\
\hline & $\mathrm{MMC}$ & $9.443 \pm 0.53 *$ & 2.560 & 39.4 \\
\hline \multirow{2}{*}{3} & Control & $4.144 \pm 0.45$ & 2.530 & 48.0 \\
\hline & MMC & $8.752 \pm 0.77^{*}$ & 2.650 & 52.0 \\
\hline \multirow{2}{*}{4} & Control & $3.671 \pm 0.52$ & 2.350 & 49.5 \\
\hline & MMC & $7.932 \pm 0.70 *$ & 2.455 & 52.0 \\
\hline \multirow{2}{*}{5} & Control & $3.143 \pm 0.41$ & 2.418 & 57.0 \\
\hline & MMC & $8.269 \pm 0.54^{*}$ & 2.549 & 48.5 \\
\hline \multirow{2}{*}{6} & Control & $2.869 \pm 0.33$ & 2.420 & 49.5 \\
\hline & MMC & $8.025 \pm * 0.50$ & 2.350 & 51.0 \\
\hline \multirow{2}{*}{7} & Control & $3.925 \pm 0.48$ & 2.535 & 51.5 \\
\hline & MMC & $8.556 \pm * 0.53$ & 2.470 & 48.5 \\
\hline \multirow{2}{*}{8} & Control & $2.556 \pm 0.36$ & 2.460 & 49.0 \\
\hline & MMC & $7.989 \pm 0.48^{*}$ & 2.530 & 44.5 \\
\hline \multirow{2}{*}{9} & Control & $4.045 \pm 0.41$ & 2.420 & 53.5 \\
\hline & MMC & $9.367 \pm 0.62 *$ & 2.385 & 50.0 \\
\hline \multirow{2}{*}{10} & Control & $3.492 \pm 0.40$ & 2.510 & 51.0 \\
\hline & MMC & $8.953 \pm 0.53 *$ & 2.630 & 48.0 \\
\hline \multirow{2}{*}{11} & Control & $3.610 \pm 0.32$ & 2.485 & 52.5 \\
\hline & MMC & $8.217 \pm 0.49^{*}$ & 2.390 & 48.0 \\
\hline \multirow{2}{*}{12} & Control & $2.854 \pm 0.36$ & 2.460 & 49.5 \\
\hline & MMC & $8.197 \pm 0.46^{*}$ & 2.455 & 51.0 \\
\hline \multirow{2}{*}{ Mean } & Control & 3.385 & 2.474 & 51.1 \\
\hline & MMC & $8.647^{* *}$ & 2.512 & 48.2 \\
\hline
\end{tabular}

${ }^{*} \mathrm{p}<0.01$ vs. control of the same healthy individual

$* * \mathrm{p}<0.01$ vs. mean control 


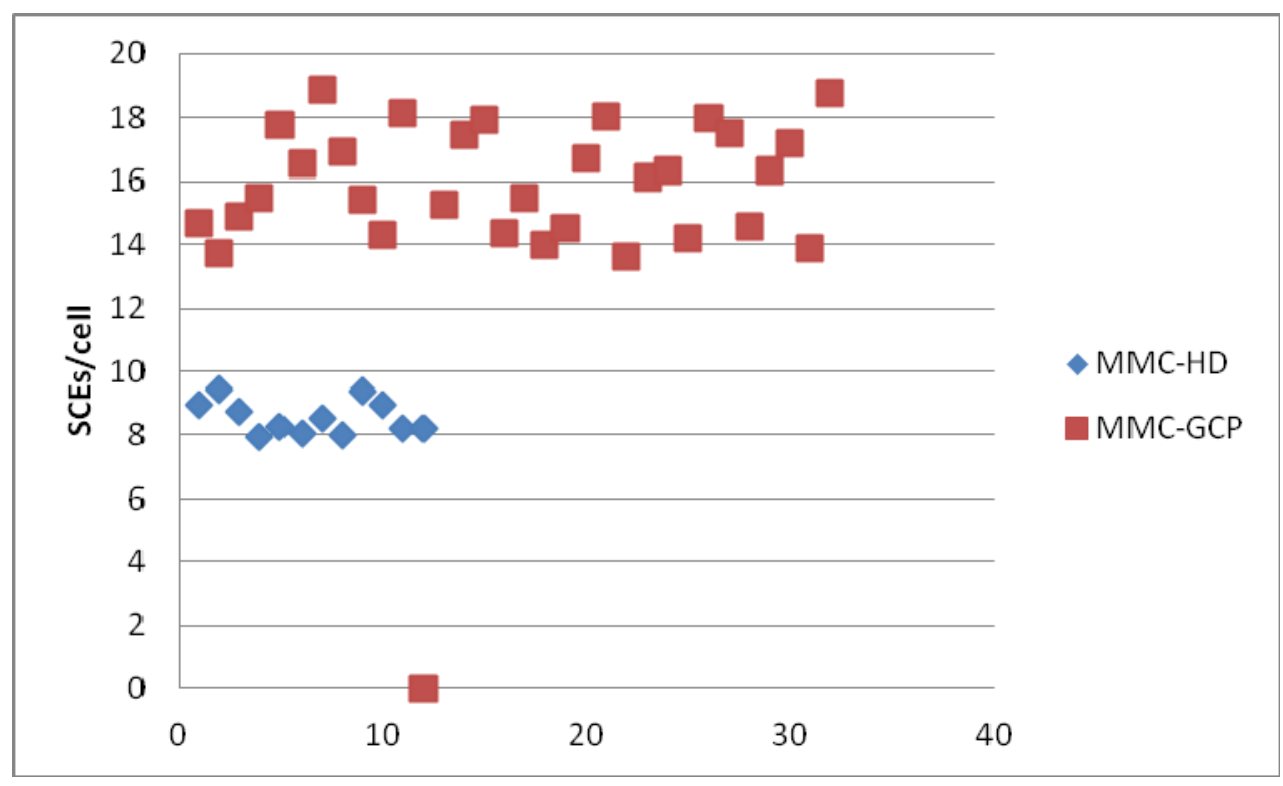

A.

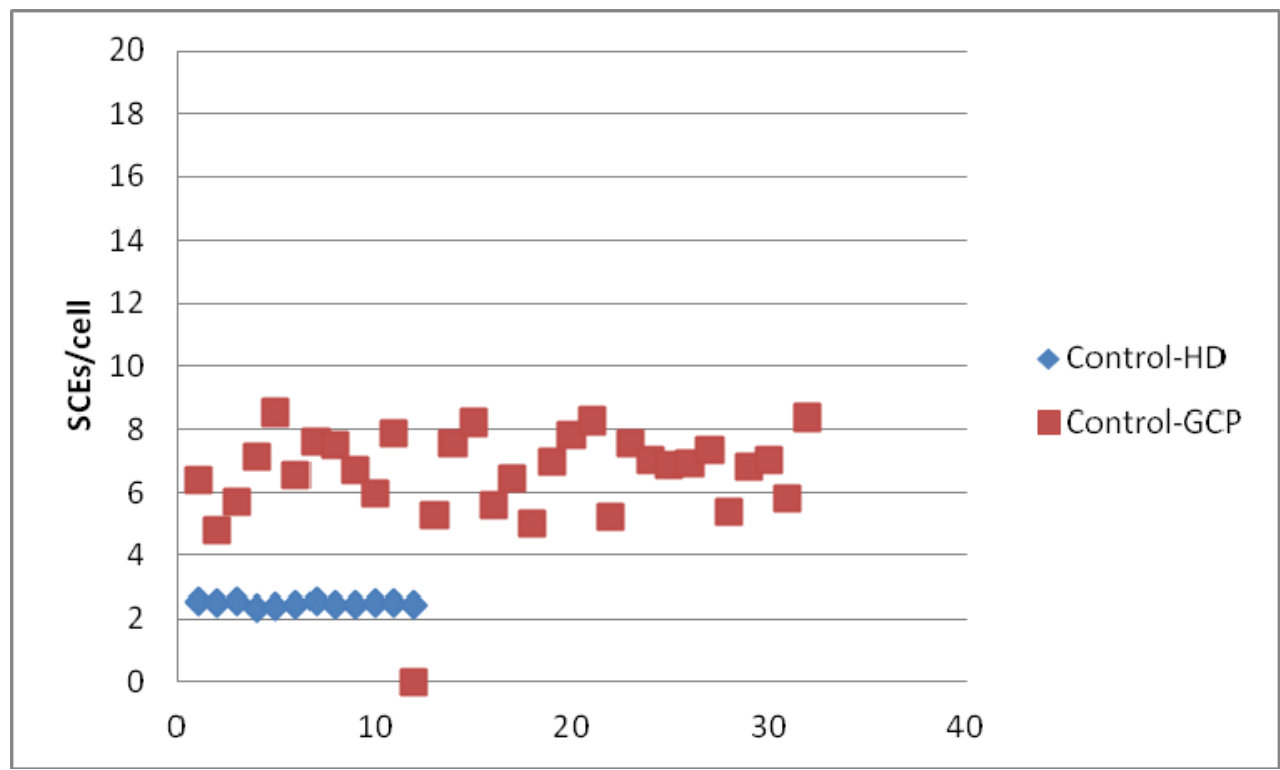

B.

Figure 2. Induction of SCEs that means enhancement of cytogenetic damage in the presence (A) or absence (B) of MMC in cultured human lymphocytes of 32 gastric cancer patients (GCP) and 12 healthy donors (HD) as shown in Tables 1 and 2.

The chromosomes of gastric cancer patients are prone to break more easily than those derived from healthy individuals. The mean SCEs frequency of gastric cancer patients lymphocytes of "control" cultures, calculated 6.691 SCEs/cell (Table 1), is significantly $(\mathrm{p}<0.01)$ higher vs. that, $3.385 \mathrm{SCEs} / \mathrm{cell}$, of healthy individuals (Table 2). The same happens between the SCEs frequencies of the treated with MMC lymphocytes of the two groups (Tables 1 and 2, Figure 2). Lymphocytes of cancer patients and healthy individuals have almost the same ability to promote their cell cycle as shown by their almost equal mean values of PRI which are 2.301 and 2.474 respectively. PRI values of lymphocytes of gastric cancer patients treated with MMC is 1.742 (Table 1) and significant $(\mathrm{p}<0.01)$ lower than that of those of healthy individuals, which PRI is 2.512 (Table 2). MI values of the lymphocytes of "control" cultures are slightly and not significant $(\mathrm{p}>0.05)$ different. The MI value of gastric 
cancer patients' lymphocytes is 40.2 (Table 1) and that of healthy donors is 51.1 (Table 2). After the lymphocytes were treated with MMC the MI values were decreased. The mean MI value of lymphocytes of gastric cancer patients treated with MMC is 22.3 and statistically significant $(p<0.01)$ lower than those of healthy individuals treated with MMC, which mean MI is 48.2.

\section{Discussion}

Gastric cancer is one of the three most common causes of death of humans worldwide. It is found that gastric cancer is much more common among people at ages of 15-29 years in Europe compared to those of the same age group in developing countries. It has been associated with nutrition and specially with high consumption of salt (Arora et al., 2010; Kono and Hirohata, 1996; Hirohata and Kono, 1997). Accumulated genetic or epigenetic alterations in a wide range of genes that control cell division, cell differentiation and cell death are the main cause of cancer (Sandberg, 1991; Parkin et al., 2001; Kono \& Hirohata, 1996; Hirohata \& Kono, 1997). Gastric cancer's development is a multi-step process which usually ranges from chronic gastritis to atrophy, intestinal metaplasia, dysplasia and finally to invasive cancer (Testino, 2004).

SCEs method is a very sensitive, rapid and practical method for detecting DNA damage induced by mutagens and/or antimutagenic agents and carcinogens and/or subsequent DNA repair. SCEs are a natural phenomenon, which occurs during the synthetic (S) phase of the cell cycle, in all multiplying somatic and genetic (germ) cells. SCEs represent the reciprocal exchange of DNA segments between sister chromatids of a chromosome, at homologous loci. They are an excellent tool for the quantitative and qualitative evaluation of DNA damage and have been widely used over the last three decades. The ability of a cell to repair DNA damage leads to SCEs formation. Cells with defects in DNA repair mechanisms, form high levels of SCEs (Lialiaris et al., 2010; Digkas et al., $2010^{\mathrm{b}}$ ). They are considered as a more sensitive method than chromosome aberrations or micronuclei, since induced DNA damage can be demonstrated by the formation of SCEs even at low concentrations of genotoxic agents (Mourelatos et al., 1983; Mourelatos 1996). It has been found that SCEs frequency is increased in cancer patients' lymphocytes suffering from many kinds of cancer such as breast cancer, uterine cervix, ovarian, prostate and gastric cancer (Zhou, 1985; Dhillon et al., 1995; Dhar et al., 1996; Dhillon \& Dhillon, 1998; Roy et al., 2000; Özturk et al., 2005; Cefle et al., 2006; Karaman et al., 2008; Aristei et al., 2009). MMC is a well known genotoxic agent which increases SCEs frequency in a wide range of cells and is widely used in order to measure chromosome fragility (Digkas et al, 2010 ${ }^{\mathrm{a}}$ ).

This study provides an evaluation of SCEs frequencies, PRIs and MIs in peripheral blood lymphocytes and their genome fragility of gastric cancer patients just after the diagnosis and prior every medication, surgery or other kind of therapy.

Baseline SCEs, PRI and MI were significantly higher in patients than in healthy donors used as controls, who were carefully selected (not smokers, without any infection for at least a month and not taking medication). Thus, gastric cancer patients show higher levels of SCEs in their lymphocytes (Zhou, 1985; Karaman et al., 2008; Zhou et al., 2010).

The SCEs frequencies of both groups' lymphocytes significant increased after treatment with MMC. The levels of SCEs of patients' lymphocytes are significant higher than that of the "control" group. Also MMC treatment induced significant higher levels of SCEs in both groups' lymphocytes, but in the group of gastric cancer patients the SCEs frequency was the higher of the two. MMC is a well known SCEs inducer. It has been referred that MMC treatment significantly increases SCEs levels in gastric cancer patients and that increase is permanent after the second injection (Ohtsuru et al., 1980). The high SCEs frequencies show that cancer patients lymphocytes' chromosomes are very fragile and much more than that of healthy individuals.

PRIs and MIs of cancer patients' lymphocytes are significant lower than that of healthy donors, so with as without MMC treatment, as a result of their inability to promote their cell cycle as fast as the healthy lymphocytes do.

In conclusion, in the present study SCEs were found significant increased in patients with gastric cancer relative to healthy controls which may be associated with the pathogenesis of gastric cancer, even it has been reported that SCEs don't have cancer predictive value (Norppa et al., 2006). Our goal was to investigate the possible chromosome instability in gastric cancer patients in the presence and in the absence of a genotoxic agent like MMC and so to reveal the underlying chromosome instability in these patients. The present data established that SCEs are sensitive markers of chemotherapy related damage, especially in the case of alkylating agents like MMC and are indicative of the attention that doctors must pay in order to avoid killing healthy cells of the patient such as lymphocytes. Further investigation in other antineoplastic drugs acting in another way but alkylation on cells and in vivo clinical studies are needed to validate our results. 


\section{References}

Aristei, C., Stracci, F., Guerrieri, P., Anselmo, P., Armellini, R., Rulli, A., ... Menghini, A. R. (2009). Frequency of sister chromatid exchanges and micronuclei monitored over time in patients with early-stage breast cancer: results of an observational study. Cancer Genet. Cytogenet., 192, 24-29. http://dx.doi.org/10.1016/j.cancergencyto.2009.02.019

Arora, R. S., Alston, R. D., Eden, T. O., Moran, A., Geraci, M., O'Hara, C., \& Birch, J. M. (2010). Cancer at ages 15-29 years: The contrasting incidence in India and England. Pediatr Blood Cancer, 58, 55-60. http://dx.doi.org/10.1002/pbc.22738

Baka, S., Ekonomopoulou, M. T., Kosmidis, C., Efthimiadis, C., \& iakovidou-Kritsi, Z. (2009). Cytogenetic effects of recombinant interferon-gamma on lymphocytes cultures from patients with non-small cell lung cancer. Cancer Genet. Cytogenet., 193, 38-43. http://dx.doi.org/10.1016/j.cancergencyto.2009.04.004

Beijnen, J. H., Lingeman, H., Van Munster, H. A., \& Underberg, W. J. (1986). Mitomycin antitumour agents: A review of their physico-chemical and analytical properties and stability. J. Pharm. Biomed. Anal., 4, 275-295. http://dx.doi.org/10.1016/0731-7085(86)80050-4

Cefle, K., Ucur, A., Guney, N., Ozturk, S., Palanduz, S., Tas, F., ... Aydiner, A. (2006). Increased sister chromatid exchange frequency in young women with breast cancer and in their first-degree relatives. Cancer Genet. Cytogenet., 171, 65-67. http://dx.doi.org/10.1016/j.cancergencyto.2006.06.005

Cortés-Gutiérrez, E. I., Cerda-Flores, R. M., \& Leal-Garza, C. H. (2000). Sister chromatid exchanges in peripheral lymphocytes from women with carcinoma of the uterine cervix. Cancer Genet. Cytogenet., 122, 121-123. http://dx.doi.org/10.1016/S0165-4608(00)00286-7

Dhar, P. K., Devi, S., Rao, T. R., Kumari, U., Joseph, A., Kumar, M. R., ... Bhat, K. R. (1996). Significance of lymphocytic sister chromatid exchange frequencies in ovarian cancer patients. Cancer Genet. Cytogenet., 89, 105-108. http://dx.doi.org/10.1016/0165-4608(95)00071-2

Dhillon, V. S., \& Dhillon, I. K. (1998). Chromosome aberrations and sister chromatid exchange studies in patients with prostate cancer: possible evidence of chromosome instability. Cancer Genet. Cytogenet., 100, 143-147. http://dx.doi.org/10.1016/S0165-4608(97)00022-8

Dhillon, V. S., Bhasker, R., Kler, R. S., \& Husain, S. A. (1995). Sister chromatid exchange (SCE) studies in breast cancer patients: a follow-up study. Cancer Genet. Cytogenet., 80, 115-117. http://dx.doi.org/10.1016/ 0165-4608(94)00175-B

Dhillon, V. S., Kler, R. S., \& Dhillon, I. K. (1996). Choromosome instabililty and sister chromatid exchange (SCE) studies in patients with carcinoma of cervix uteri. Cancer Genet. Cytogenet., 86, 54-57. http://dx.doi.org/10.1016/0165-4608(95)00168-9

Digkas, E., Chrisafi, S., Passadaki, T., Tsalkidis, A., Hatzimichail, A, Vargemezis, V., \& Lialiaris, T. S. (2010a). In vitro and in vivo cytogenetic effects of recombinant human erythropoietin on the frequency of Sister Chromatid Exchanges (SCEs) alone or in combination with MMC. Chemotherapy, 56, 239-247. http://dx.doi.org/10.1159/000316849

Digkas, E., Kareli, D., Chrisafi, S., Passadaki, T., Mantadakis, E., Hatzimichail, A., ... Lialiaris, T. (2010b). Attenuation of cytogenetic effects by erythropoietin in human lymphocytes in vitro and P388 ascites tumor cells in vivo treated with irinotecan (CPT-11). Food Chem. Toxicol., 48, 242-49. http://dx.doi.org/10.1016 /j.fct.2009.10.007

Duydu, Y., Ustundag, A., Aydin, A., Eken, A., Dündar, K., \& Yzun, G. (2006). Increased sensitivity to mitomycin $\mathrm{C}$-induced sister chromatid exchange in lymphocytes from patients undergoing hyperbaric oxygen therapy. Environ. Mol. Mutagen., 47, 185-191. http://dx.doi.org/10.1002/em.20184

Etokebe, G., Kneževic, J., Petričević, B., Pavelić, J., Vrbanec, D., \& Dembić, Z. (2009). Single-Nucleotide Polymorphisms in Genes Encoding Toll-Like Receptor -2, -3, -4, and -9 in Case-Control Study with Breast Cancer. Genet. Test. Mol. Biomarkers, 13, 729-734. http://dx.doi.org/10.1089/gtmb.2009.0045

Goto, K., Maeda, S., Kano, Y., \& Sugiyama, T. (1978). Factors involved in differential Giemsa-staining of sister chromatids. Chromosoma, 66, 351-359. http://dx.doi.org/10.1007/BF00328535

Hirohata, T., \& Kono, S. (1997). Diet/nutrition and stomach cancer in Japan. Int. J. Cancer, 10, 34-36. http://dx.doi.org/10.1002/(SICI)1097-0215(1997)10+<34::AID-IJC9>3.3.C O;2-5 
Hu, D., Tong, S., Wei, R., Hui Z., Haidan, L., Zhi, D., ... Ya, C. (2008). The Polymorphisms on Igk Gene Are Related to Susceptibility of Breast Cancer and Gastric Cancer. Genet. Test. Mol. Biomarkers, 12, 575-580. http://dx.doi.org/10.1089/gte.2008.0062

Karaman, A., Binici, D. N., Kabalar, M. E., Dursun, H., \& Kurt, A. (2008). Alteration of sister chromatid exchange frequencies in gastric cancer and chronic atrophic gastritis patients with and without H. pylori infection. World J. Gastroenterol., 14, 2534-2539. http://dx.doi.org/10.3748/wjg.14.2534

Karapidaki, I., Bakopoulou, A., Papageorgiou, A., Iakovidou, Z., Mioglou, E., Nikolaropoulos, S., ... Lialiaris, T. (2009). Genotoxic, cytostatic, antineoplastic and apoptotic effects of newly synthesized antitumour steroidal esters. Mutat Res., 675, 51-59. http://dx.doi.org/10.1016/j.mrgentox.2009.02.010

Ke-Xiang, Z., Yu-Min, L., Xun, L., Wen-Ce, Z., Yong, S., \& Tao, L. (2012). Study on the association of p53 codon 72 polymorphisms with risk of gastric cancer in high incidence Hexi area of Gansu Province in China. Mol. Biol. Rep., 39, 723-728. http://dx.doi.org/10.1007/s11033-011-0791-5

Kono, S., \& Hirohata, T. (1996). Nutrition and stomach cancer. Cancer Causes Control, 7, 41-55. http://dx.doi.org/10.1007/BF00115637

Latt, S. A., Stetten, G., Juergens, L. A., Buchanan, G. R., \& Gerald, P. S. (1975). Induction by alkylating agents of sister chromatid exchanges and chromatid breaks in Fanconi's anemia. Proc. Natl. Acad. Sci. U S A., 72, 4066-4070. http://dx.doi.org/10.1073/pnas.72.10.4066

Lialiaris, T., Kouskoukis, A., Tiaka, E., Digkas, E., Beletsiotis, A., Vlasis, K., ... Natsis, K. (2010). Cytogenetic damage after ischemia and reperfusion. Genet. Test. Mol. Biomarkers, 14, 471-5. http://dx.doi.org/10.108 9\%2Fgtmb.2009.0194

Lialiaris, T., Lyratzopoulos, E., Papachristou, F., Simopoulou, M., Mourelatos, C., \& Nikolettos, N. (2008). Supplementation of melatonin protects human lymphocytes in vitro from the genotoxic activity of melphalan. Mutagenesis, 23, 347-354. http://dx.doi.org/10.1093/mutage/gen020

Lialiaris, T., Mourelatos, D., Boutis, L., Papageorgiou, A, Christianopoulou, M., Papageorgiou, V., \& Dozi-Vassiliades, J. (1989). Comparative study on cytogenetic effects by diplatinum complexes of the ligands of naphthazarine and squaric acid in human lymphocytes. J. Pharmacol. Exp. Ther., 251, 368-371.

Lialiaris, T., Mourelatos, D., \& Dozi-Vassiliades, J. (1987). Enhancement and attenuation of cytogenetic damage by vitamin $\mathrm{C}$ in cultured human lymphocytes exposed to thiotepa or L-ethionine. Cytogenet. Cell Genet., 44, 209-214. http://dx.doi.org/10.1159/000132373

Lialiaris, T., Mourelatos, D., Stergiadou, H. C., \& Constantinidou, H. A. (1990). Cytogenetic study for possible mutagenic activity induced by ice-nucleation bacteria or their metabolic products in human lymphocytes in vitro. Mutat. Res., 242, 163-168. http://dx.doi.org/10.1016/0165-1218(90)90043-2

Lialiaris, T., Polyzou, A., Mpountoukas, P., Tsiggene, A., Kouskoukis, A., Pouliliou, S., ... Chatzimichail, A. (2009). Chromosome instability on children with asthma. J Asthma, 46, 841-844. http://dx.doi.org/10.3109/ 02770900903171432

Mourelatos, D. (1996). Chromosome study as predictor of chemoresponse of tumours. Cancer Journal, 9, 136-141.

Mourelatos, D., Dozi-Vassiliades, J., Tsigalidou-Balla, V., \& Granitsas, A. (1983). Enhancement by methylxanthines of sister-chromatid exchange frequency induced by cytostatics in normal and leukemic human lymphocytes. Mutat Res., 121, 147-152 http://dx.doi.org/10.1016/0165-7992(83)90113-6

Norppa, H., Bonassi, S., Hansteen, I. L., Hagmar, L., Stromberg, U., Rossner, P., ... Fucic, A. (2006). Chromosomal aberrations and SCEs as biomarkers of cancer risk. Mutat. Res., 600, 37-45. http://dx.doi.org/10.1016/j.mrfmmm. 2006.05.030

Ohtsuru, M., Ishii, Y., Takai, S., Higashi, H., \& Kosaki, G. (1980). Sister chromatid exchanges in lymphocytes of cancer patients receiving mitomycin C treatment. Cancer Res., 40, 477-480.

Öztürk, S., Palanduz, S., Cefle, K., Tutkan, G., Ucur, A., Dincol, G., ... Kucukkaya, R. D. (2005). Genotoxicity and sister chromatid exchange in patients with myelodysplastic disorders. Cancer Genet. Cytogenet., 159, 148-150. http://dx.doi.org/10.1016/j.cancergencyto.2004.10.006

Papachristou, F., Lialiaris, T., Touloupidis, S., Kalaitzis, C., Simopoulos, C., \& Sofikitis, N. (2006). Evidence of increased chromosomal instability in infertile males after exposure to mitomycin $\mathrm{C}$ and caffeine. Asian $\mathrm{J}$. Androl., 8, 199-204. http://dx.doi.org/10.1111/j.1745-7262.2006.00084.x 
Parkin, D. M., Bray, F. I., \& Devesa, S. S. (2001). Cancer burden in the year 2000. The global picture. Eur. J. Cancer, 37, S4-66. http://dx.doi.org/10.1016/S0959-8049(01)00267-2

Pasechnikov, V. D., Chukov, S. Z., Kotelevets, S. M., Mostovov, A. N., Mernova, V. P., \& Polyakova, M. B. (2004). Possibility of non-invasive diagnosis of gastric mucosal precancerous changes. World $J$. Gastroenterol., 10, 3146-3150.

Roy, S. K., Trivedi, A. H., Bakshi, S. R., Patel, R. K., Shukla, P. H., Patel, S. J., ... Shah, P. M. (2000). Spontaneous chromosomal instability in breast cancer families. Cancer Genet. Cytogenet., 118, 52-56. http://dx.doi.org/10.1016/S0165-4608(99)00191-0

Sandberg, A. A. (1991). Chromosome abnormalities in human cancer and leukemia. Mutat. Res., 247, 231-40. http://dx.doi.org/10.1016/0027-5107(91)90019-K

Sarto, F., Faccioli, M. C., Cominato, I., \& Levis, A. G. (1985). Aging and smoking increase the frequency of sister-chromatid exchanges (SCE) in man. Mutat. Res Letters., 144(3), 183-187. http://dx.doi.org/10.1016/ 0165-7992(85)90137-X

Sarto, F., Mustari, L., Mazzotti, D., Tomanin, R., \& Levis, A. G. (1987). Variations of SCE frequencies in peripheral lymphocytes of ex-smokers. Mutat. Res. Letters, 192, 157-162. http://dx.doi.org/10.1016/01657992(87)90114-X

Sartorelli, A. C. (1986). The role of mitomycin antibiotics in the chemotherapy of solid tumors. Biochem. Pharmacol., 35, 67-69. http://dx.doi.org/10.1016/0006-2952(86)90559-9

Testino, G. (2004). Gastric preneoplastic changes. Recenti. Prog. Med., 95, 239-244.

Vogelstein, B., \& Kinzler, K. W. (2004). Cancer genes and the pathways they control. Nat. Med., 10, 789-799. http://dx.doi.org/10.1038/nm1087

Wenger, S. L. (1995). Chemical induction of sister chromatid exchange at fragile sites. Cancer Genet. Cytogenet., 85, 72-74. http://dx.doi.org/10.1016/0165-4608/895/900137-9

Yasui, W., Oue N., Kuniyasu, H., Ito, R., Tahara, E., \& Yokozaki, H. (2001). Molecular diagnosis of gastric cancer: present and future. Gastric Cancer, 4, 113-121. http://dx.doi.org/10.1007/PL00011733

Zhou, L. (1985). Sister chromatid exchange in gastric cancer, chronic atrophic gastritis and normal control. Zhonghua Zhong Liu Za Zhi, 7, 257-259.

Zhou, Y., Li, N., Zhuang, W., \& Wu, X. (2010). p53 Codon 72 Polymorphism and Gastric Cancer Risk in a Chinese Han Population. Genet. Test. Mol. Biomarkers, 14, 829-833. http://dx.doi.org/10.1089/gtmb.2010. 0115 